\title{
The Utility of a Digital Platform to Help Specialists Training in The Management of Headaches: An Italian Experience
}

\author{
Vincenzo Raieli*1, Luca Maria Messina ${ }^{2}$, Flavia Drago ${ }^{2}$, Luigi Vetri ${ }^{2}$ and Filippo Brighina ${ }^{3}$ \\ ${ }^{1}$ UO NPI - ISMEP - ARNAS Civico Palermo, Italy \\ ${ }^{2}$ Child Neuropsychiatry School, Italy
}

${ }^{3}$ Department of Experimental Biomedicine and Clinical Neurosciences, Italy

*Corresponding author: Vincenzo Raieli, UO NPI - ISMEP - ARNAS Civico Palermo, Italy

\begin{tabular}{|c|c|}
\hline ARTICLE INFO & ABSTRACT \\
\hline Received: 慧 February 01, 2019 & Citation: Vincenzo R, Luca Maria M, Flavia D, Luigi V, Filippo B. The Utility of a Digit \\
\hline 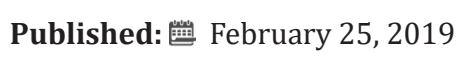 & $\begin{array}{l}\text { form to Help Specialists Training in The Management of Headaches: An Italian Experience. } \\
\text { Biomed J Sci \& Tech Res 15(1)-2019. BJSTR. MS.ID.002650. }\end{array}$ \\
\hline
\end{tabular}

\section{Introduction}

The primary headaches, especially migraine, are an increasing epidemiological disorder with an important impact on the public health. Migraine is at the seventh place among the more disabling disorders, more than demyelinating diseases or epilepsies. The prevalence is around $7.7 \%$, involving a range of age between 2 and 70 years. However only in Italy less than $30 \%$ of patients have been visited by family physicians, $14 \%$ consulted a headache specialist and only $4 \%$ followed a prophylactic therapy [1]. Migraine is considered an "iceberg disease" where the unknown disease to doctors is greater than known disease [1,2]. These specific features are undervalued, likely due to an underestimation of the problem by health policies $[3,4]$, with a deep negative impact on the practice of general doctors (unrecognition and/or undertreatment of primary headaches, over-reliance on emergency departments etc), pediatricians and headache specialists (superficial approach to a complex disease, reduced adherence to guidelines, poor communication among pediatric and adult headache specialist with general doctors or pediatricians or other specialists) [4-6].

For these reasons it is very important for specialists to have an adequate training for the headache management, however the reported epidemiological, clinical and treatment data suggest that it is far from being optimal [1]. The increasing development of digital instruments (digital platforms, web sites, social networks, and similar) seems to be a great help, but is it really true? Our recent studies [7-8] have pointed out that, after 2-4 years of experience, a digital platform dedicated to headaches, even though free and easy to use, stimulates the passive, but not active use of the platform. These studies have also shown that there is no difference in its use between headache specialists and other specialists. We observed a paradoxical contrast between the increasing interest on this instrument (exponential increase of subscription to platform for headaches) and its consequent poor use by the registered specialists [7-8]. Here we want to understand if this behavior depends on the topics offered in the platform and we want to compare this behavior to that of similar platforms dedicated to other health topics. We also did a synthetic analysis after more than 4 years from the functioning of the platform.

\section{Methods}

We have already previously described in a more extended way what this platform consists of (for more details refer to this reference [8]. In summary: with the technological support of an industrial sponsor (Janssen) the digital platform has been active online since 1 October 2014. The platform is easily accessible to doctors via free registration and approval of the group's administrators. It is divided in two sections: a section for pediatric headaches and a section for adult headaches. The uploaded resources consist of different materials concerning headache: a folder including more than 100 articles dedicated to migraine with aura, a lot of books and 
over one hundred PowerPoint's presentations dedicated to primary episodic headaches, chronic, secondary headaches and neuralgias, three atlas of Neuroradiology specific for headaches, collections of artistic images on migraine and neuroimaging pictures related to headaches, various clinical material for headache monitoring and treatment such as medical records, diary cards, models of diet, physical exercises etc. Furthermore, members can discuss clinical cases or submit new cases or topics $[9,10]$.

Users can choose to receive notifications for each new contribution by email. We have also created a WhatsApp group to alert members about each new contribution and to encourage real-time communication. From 1 January 2018 an app to access the platform from smartphone is available. The system allows the administrators to monitor the platform members' activity: number of access, number and types of uploaded and /or downloaded resources, submission of clinical cases and participation to discussions [11,12]. We took into account the evolution of the platform's activities over time, both in upload and in download, we observed the more downloaded topics and measured the average download for user. Finally, we asked to the technological supporter the descriptive data on the use of other digital platforms, to compare our experience with other experiences.

\section{Results}

After two years, the platform members were 37 (14 in common for the two sections), while at the fourth year they were 67 (44 in both sections). 74 resources were uploaded during the first two years and other 64 during the following two (almost $90 \%$ only by one member). In the first two years the downloads were 486 (average: 13,1 downloads per member), active members were 22/37 (59.5\%), 5 clinical cases were included in the platform; in the following two years the downloads were 940 (average: 14 downloads per member), active members were $49 / 67$ (71\%), no further clinical cases were submitted. WhatsApp group members were 61 , however $33 / 61$ have actively participated with more than two interventions. The smartphone app has been downloaded by 19 members (19/61), 12 members have not downloaded it for several reasons, other members have not answered to the administrator's questions about the knowledge and use of the app. To this day the section of the platform dedicated to adult headaches is made up of 60 members, among them the active users (users who accessed the platform at least one time) are 50 (83\%); the total number of the resources available is 123 which have been downloaded 700 times. On average, each user has done 14 downloads.

The section of the platform dedicated to pediatric headaches is, up to date, made up of 67 members, among them the active users are 52 (77\%); the total number of the resources available is 148, which have been downloaded 1012 times. On average, each user has done 19 downloads. 53 users are enrolled in both the sections of the platform. As it is possible to observe from the activity performance charts, in the last 24 months there has been an increase in the number of downloads together with the upload of new resources or immediately after the new uploads, while summer months are characterized by a remarkable decrease in the number of downloads, uploads and new contributions.

\section{Discussion and Conclusion}

After 4 years the monitoring of the platform activity shows that social networks dedicated to headaches are appreciated by the scientific community because there has been an increase of about $80 \%$ in subscriptions to the platform. However, the activity does not appear to significantly increase (same average of downloads and uploads per member, a slight increase in the number of active members). Neither the possibility of a WhatsApp group nor of a smartphone app seems to modify this trend. These data confirm the limits in the efficacy of these digital instruments in the headache training for specialists. The other platforms show that discussions and downloads are much less than the number of subscribers, similarly to the activity of our platform. In Table 1 we summarized the activity of other digital platforms dedicated to different disorders (number of members, uploads and downloads). The analysis of the data implemented in this study allows us to evaluate with greater attention what are the strengths and weaknesses of using a digital platform in the scientific study of headaches and what is the development of interactions between registered physicians, also comparing it to data relating to digital platforms specific to other diseases.

Table 1: we summarized the activity of other digital platforms dedicated to different disorders (number of members, uploads and downloads).

\begin{tabular}{|c|c|c|c|c|}
\hline & Members & Active members & Downloads & Discussions \\
\hline JBOARD CLUB - adult headaches & 60 & $50(83 \%)$ & 700 & 3 \\
\hline JBOARD CLUB - pediatric headaches & 67 & $52(77 \%)$ & 1012 & 3 \\
\hline JBOARD CLUB Algology Groups: 8 & 84 & $37(44 \%)$ & 84 & 180 \\
\hline JBOARD CLUB Dermatology Groups: 3 & 33 & $16(48 \%)$ & 13 & 8 \\
\hline JBOARD CLUB Hematology Groups: 4 & 82 & $19(23 \%)$ & 19 & 1 \\
\hline JBOARD CLUB Digestive Endoscopy Groups: 1 & 17 & $8(47 \%)$ & 0 & 3 \\
\hline JBOARD CLUB Gastroenterology Groups: 13 & 183 & $70(38 \%)$ & 260 & 11 \\
\hline JBOARD CLUB Immunology Groups: 1 & 5 & $2(40 \%)$ & 0 & 0 \\
\hline
\end{tabular}




\begin{tabular}{|c|c|c|c|c|}
\hline JBOARD CLUB Infectiology Groups: 2 & 3 & $2(67 \%)$ & 0 & 0 \\
\hline JBOARD CLUB Nephrology Groups: 1 & 19 & $2(11 \%)$ & 0 & 1 \\
\hline JBOARD CLUB Neurology Groups: 3 & 121 & $98(81 \%)$ & 1437 & 54 \\
\hline JBOARD CLUB Oncology Groups: 8 & 86 & $42(49 \%)$ & 163 & 9 \\
\hline JBOARD CLUB Psychiatry Groups: 2 & 201 & $45(22 \%)$ & 32 & 1 \\
\hline
\end{tabular}

We therefore have the opportunity to state that the interest aroused by our digital platform is greater than that of specific platforms for other diseases, based on objective parameters such as number of subscribers, interactions and downloads. In addition, the data show that the items that most capture the attention of registered colleagues are those of the fastest use and those closely related to real clinical cases. This data probably highlights the usefulness of the platform as a tool for sharing and comparing, representing a possible aid in complex clinical cases in terms of approach and differential diagnosis. Furthermore, we have highlighted that PowerPoint presentations are of particular interest, probably representing a quick and exhaustive tool for deepening knowledge. Less interest showed those contents that require more time reading and attention or those related to less common aspects of diseases. In Table 2 we reported the most downloaded items. In order to increase the use of these instruments and to improve the specialists training it would probably be necessary to make their use mandatory or to encourage it through institutional and economic credits.

Table 2: we reported the most downloaded items.

\begin{tabular}{|c|c|}
\hline Files & N. Of Downloads \\
\hline Headache treatment PowerPoint & 72 \\
\hline Article: When to investigate headache & 69 \\
\hline Master in headache PowerPoint & 48 \\
\hline Migraine aura videos & 37 \\
\hline Innovation in migraine & 36 \\
\hline Continuum neurology & 36 \\
\hline Dysphagia and neuromuscular disease PowerPoint & 31 \\
\hline Secondary headaches PowerPoint & 29 \\
\hline $\begin{array}{l}\text { Group IV headaches (according to ICHD III) } \\
\text { PowerPoint }\end{array}$ & 23 \\
\hline Secondary headaches algorithm & 22 \\
\hline Gadsby pathophysiology & 21 \\
\hline Neuroradiology atlas & 21 \\
\hline Chronic headache PowerPoint & 21 \\
\hline Migraine with Aura PowerPoint & 11 \\
\hline Book: Comorbidities and headache & 7 \\
\hline Book: Pediatric comorbidity and headache & 5 \\
\hline
\end{tabular}

\section{References}

1. Nicolucci A, Rossi MC (2013) Facts and figures about Migraine in Italy. Public Health \& Health Policy 2: 1-3.

2. Bale JF Jr, Currey M, Firth S, Larson R (2009) Executive Committee of the Child Neurology Society. The Child Neurology Workforce Study: pediatrician access and satisfaction. J Pediatr 154(4): 602-606.

3. (2011) World Health Organization Atlas of headache disorders and resources in the world. 2011 ISBN: 9789241564212.

4. Brighina F, Raieli V, La Pegna G, F Lanaia F (2006) Disability and social impact of headaches and migraine. The role of information and cooperation among patient, general practitioner and specialist: A project of the SISC Sicilia. Giornale delle Cefalee 2: 10-12.

5. Albers L, Straube A, Landgraf MN, Filippopulos F, Heinen F et al. (2015) Migraine and tension type headache in adolescents at grammar school in Germany burden of disease and health care utilization. J Headache Pain 16: 52.

6. Raieli V, Compagno A, Puma D, La Vecchia M, Pandolfi E, et al. (2010) Headache: What do children and mothers expect from pediatricians? Headache 50 (2): 290-300.

7. Raieli V, Correnti E, Sandullo A, Romano M, Marchese F, et al. (2018) Effectiveness of a digital platform for sharing knowledge on headache management: a twoyear experience. Funct Neurol Jan/Mar 33(1): 51-55.

8. Raieli V, Loiacono C, Messina LM, Correnti E, Brighina F, et al. (2018) Is a digital platform useful in headache training? A 4-year Italian experience. Neurol Sci. Dec 39(12): 2223-2224.

9. Ahmed ZA, Faulkner LR (2016) Headache Education in Adult Neurology Residency: A Survey of program Directors and Chief Residents. Headache 56(5): 871-877.

10. Minen MT, Monteith T, Strauss LD, Starling (2015) A New Investigator and Trainee Task Force Survey on the Recruitment and Retention of Headache Specialists. Headache 55(8): 1092-1101.

11. Minen M, Shome A, Halpern A, Tishler L, Brennan KC, et al. (2016) A migraine management training program for primary care providers: An overview of a survey and pilot study findings lessons learned and considerations for further research. Headache 56(4): 725-740.

12. Weber M, Daurès JP, Fabre N, Druais PL, Dardenne J, et al. (2002) Influence of general practitioners' personal knowledge on migraine in medical attitudes towards their patients ${ }^{1}$ suffering from migraine. Rev Neurol 158: 439-445. 
ISSN: 2574-1241

DOI: 10.26717/BJSTR.2019.15.002650

Vincenzo Raieli. Biomed J Sci \& Tech Res

(c) (i) This work is licensed under Creative

Submission Link: https://biomedres.us/submit-manuscript.php

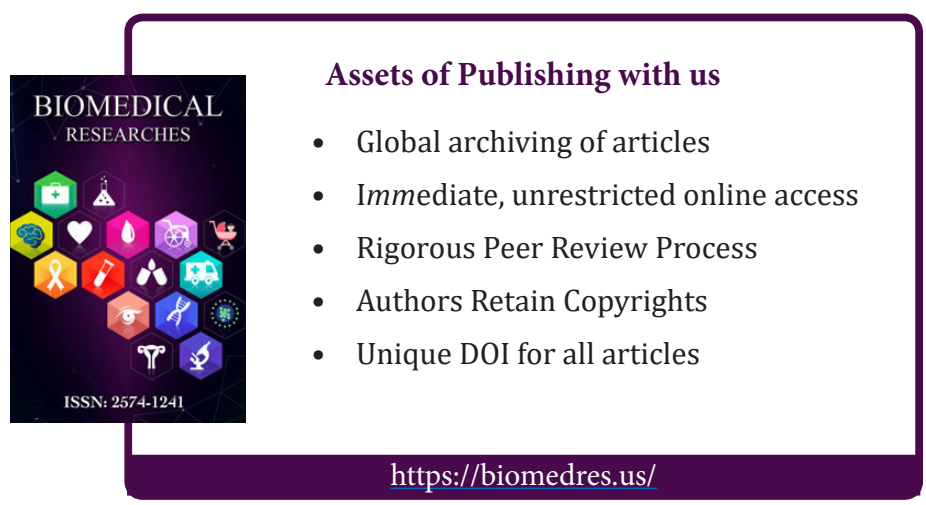

